\title{
Cardiothoracic
}

Transplantation

\section{Survival benefit of lung transplantation for patients with idiopathic pulmonary fibrosis}

\author{
Gabriel Thabut, MD \\ Hervé Mal, MD ${ }^{a}$ \\ Yves Castier, $\mathrm{MD}^{\mathrm{b}}$ \\ Odile Groussard, $\mathrm{MD}^{\mathrm{c}}$ \\ Olivier Brugière, $M D^{\mathrm{a}}$ \\ Rolana Marrash-Chahla, MDa \\ Guy Lesèche, $M D^{b}$ \\ Michel Fournier, MD
}

From the Service de Pneumologie et Réanimation Respiratoire, ${ }^{\text {a }}$ Service de Chirurgie Thoracique et Vasculaire, ${ }^{\mathrm{b}}$ and Service d'Anatomopathologie, Hôpital Beaujon, ${ }^{c}$ Clichy, France.

There was no conflict of interest in connection with this study, and the authors received no financial support for this study.

Received for publication July 22, 2002; revision requested Aug 22, 2002; revision received Nov 22, 2002; accepted for publication Dec 4, 2002.

Address for reprints: Gabriel Thabut, MD, Service de Pneumologie et Réanimation, Hôpital Beaujon, 100 avenue du Général Leclerc, 92110, Clichy, France (E-mail: gabriel.thabut@bjn.ap-hop-paris.fr).

J Thorac Cardiovasc Surg 2003;126:469-75

Copyright $\odot 2003$ by The American Association for Thoracic Surgery

$0022-5223 / 2003 \$ 30.00+0$

doi:10.1016/S0022-5223(03)00600-7
Objective: Although lung transplantation is viewed as an acceptable option for patients with end-stage idiopathic pulmonary fibrosis, the survival benefit of this approach is still debated. This study examined whether there was a survival benefit of lung transplantation in a cohort of patients referred to our transplant center with a diagnosis of idiopathic pulmonary fibrosis according to American Thoracic Society criteria.

Methods: Forty-six patients accepted for lung transplantation during a 12-year period with a diagnosis of idiopathic pulmonary fibrosis form the basis of this study. Survival benefit offered by lung transplantation was assessed using Cox proportional-hazards modeling, with patients on a waiting list as the control group.

Results: Twenty-eight patients underwent lung transplantation (27 single and 1 double), 16 patients died while waiting, and 2 patients remained on the active waiting list. Diagnosis of idiopathic pulmonary fibrosis was made on histologic examination of the explanted lung or lung biopsy before lung transplantation. There was a pattern of usual interstitial pneumonia in 31 cases $(67 \%)$. The 15 remaining patients fulfilled all American Thoracic Society criteria for idiopathic pulmonary fibrosis. The median waiting time for organs was 51 days. Survival after lung transplantation was $79.4 \%$ at 1 year, $63.5 \%$ at 2 years, and $39 \%$ at 5 years. The multivariable analysis showed that lung transplantation reduced the risk of death by $75 \%$ (95\% confidence interval, $8 \%-86 \% ; P=.03$ ) after adjustment on potential confounding variables.

Conclusions: Lung transplantation is effective in improving the survival of selected patients affected by idiopathic pulmonary fibrosis.

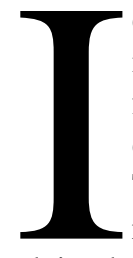

diopathic pulmonary fibrosis (IPF) is a chronic, progressive, fatal form of interstitial lung disease. ${ }^{1-3}$ The median survival of patients with IPF ranges from $2.8^{4}$ to 4.8 years $^{5}$ after diagnosis, depending on the stage of the disease, ${ }^{5,6}$ histopathologic features, ${ }^{7}$ and response to medical treatment. The course of the disease is not easily predictable because of the variable rates of progression from patient to patient. This poor prognosis is explained by the poor responsiveness to currently available treatments including 
TABLE 1. Characteristics of patients at time of acceptance for transplantation

\begin{tabular}{|c|c|c|c|c|}
\hline Variables (units) & $\begin{array}{l}\text { All patients } \\
n=46\end{array}$ & $\begin{array}{c}\text { Patients who received } \\
\text { transplants } \\
n=28\end{array}$ & $\begin{array}{l}\text { Patients who did not receive } \\
\text { transplants } \\
n=16\end{array}$ & $P$ \\
\hline Age (yr) & $50.1(44.0-58.3)$ & $49.3(41.3-55.6)$ & $52.9(48.3-60.3)$ & .3 \\
\hline Male/female & $33(71.7 \%)$ & $20(71.4 \%)$ & $11(68.8 \%)$ & .9 \\
\hline Height $(\mathrm{cm})$ & $172.0(163.0-175.0)$ & $174.0(163.0-178.0)$ & $168.5(162.0-172.0)$ & .07 \\
\hline Weight $(\mathrm{kg})$ & $73.0(60.0-78.0)$ & $76.0(64.0-84.0)$ & $63.5(54.0-75.0)$ & .03 \\
\hline Body mass index & $24.7(22.0-27.1)$ & $25.7(22.9-27.4)$ & $23.7(20.0-25.1)$ & .06 \\
\hline Corticosteroid therapy (mg) & $19.0(10.0-25.0)$ & $18.0(10.0-20.0)$ & $22.5(4.5-45.0)$ & .3 \\
\hline Corticosteroid therapy (n) & $39(84.8 \%)$ & $25(89.3 \%)$ & $13(81.3 \%)$ & .7 \\
\hline
\end{tabular}

Boldface indicates statistical significance.

steroids and cytotoxic agents. Conversely, lung transplantation (LTx) has been demonstrated to be a viable option in these patients, the median of survival being approximately 36 months in the International Registry. ${ }^{8}$ In comparison with natural history, the survival benefit conferred by LTx in case of pulmonary fibrosis has been suggested,,${ }^{9-11}$ but the question has not been answered definitively. In particular, Hosenpud and colleagues ${ }^{11}$ compared the survival of patients on a waiting list and after LTx in the US Registry and found that LTx conferred a survival benefit in cases of interstitial pulmonary fibrosis. However, the difference in survival did not reach statistical significance. Moreover, the patients were classified with interstitial pulmonary fibrosis irrespective of histologic considerations, which can be misleading, because without LTx, the prognosis of various types of interstitial lung diseases differs markedly. ${ }^{4,12}$ From our own data, we assessed the survival benefit provided by LTx in a homogeneous sample of patients with a diagnosis of IPF according to American Thoracic Society (ATS) criteria. By use of the Cox proportional-hazards modeling, we analyzed the survival benefit offered by LTx in our center, with patients on a waiting list as the control group.

\section{Methods \\ Patients}

From March 1988 to July 2001, 181 patients were accepted on a waiting list for LTx at Hôpital Beaujon. Of these patients, 149 underwent LTx, and 32 died while waiting. We restricted our analysis to 46 patients who had a diagnosis of IPF according to ATS criteria. ${ }^{1}$ These patients form the basis of the study. Particular attention was paid to exclude patients with a history of collagen vascular disease, allergic alveolitis, exposure to mineral and organic dusts, or drug toxicity. All patients had been treated with corticosteroids, some of them with various drug regimens (1 patient had received interferon gamma therapy, and 10 patients had received immunosuppressive drugs [cyclophosphamide or azathioprine]) before referral to our institution. Selection of patients for LTx was made according to international guidelines. ${ }^{13}$ Patients with severe pulmonary hypertension (mean pulmonary artery pressure $>40 \mathrm{~mm} \mathrm{Hg}$ ) were not considered for transplantation in our center.

\section{Lung and Heart Physiology}

Pulmonary function tests were performed according to the ATS standards, and customary normal reference values were used for spirometry, lung volumes, and diffusing capacity. Lung volumes were measured by plethysmography. Exercise capacity was assessed by a standardized 6-minute walk test. Left ventricular ejection fraction was measured by gated equilibrium radionuclide ventriculography after a peripheral intravenous injection of 750 $\mathrm{MBq}$ technetium-99m human serum albumin. Right heart catheterization was performed in all patients using a standard technique. Cardiac output was measured by the thermodilution technique. Coronary angiography was performed when left heart dysfunction was suspected.

\section{Organ Allocation and Transplantation Procedure}

When the organs became available, the decision on organ allocation was made by a senior member of the transplant team according to the severity of each patient but irrespective of the waiting time of each recipient. Donor selection was based on widely accepted guidelines. ${ }^{14}$ Donor and recipient matching were based on ABO compatibility and cytomegalovirus status. Single LTx was performed using a classic technique, ${ }^{15}$ whereas bilateral LTx was a bilateral sequential operation. ${ }^{16}$ Our policy was to perform single LTx except in case of significant bronchiectasis. Immunosuppression was administered as previously described. ${ }^{17}$

\section{Follow-up}

Routine medical management was continued during the waiting period under the supervision of the transplant physician. After LTx, patients were seen at regular intervals at the outpatient clinic and were asked to refer to the transplant center in case of unusual symptoms or in case of functional impairment.

\section{Statistical Analysis}

Date of entry in the study was the date of listing for transplantation, and all measurements taken at this time were used in the analysis. Continuous data are expressed as median (25th-75th percentile), and categorical data are expressed as counts and proportions. Survival after transplantation was estimated by the Kaplan-Meier method. Cox proportional hazards regression was used to assess the survival effect of LTx after adjustment on potential confounders. ${ }^{18}$ All variables listed in Tables 1 and 2 were 
TABLE 2. Cardiopulmonary features of patients when evaluated for lung transplantation

\begin{tabular}{|c|c|c|c|c|}
\hline Variables (units) & $\begin{array}{l}\text { All patients } \\
n=46\end{array}$ & $\begin{array}{l}\text { Patients who received transplants } \\
\qquad n=28\end{array}$ & $\begin{array}{l}\text { Patients who did not receive transplants } \\
\qquad n=16\end{array}$ & $\boldsymbol{P}$ \\
\hline \multicolumn{5}{|l|}{ Pulmonary function } \\
\hline FVC, L & $1370(1000-1670)$ & $1500(1030-1750)$ & $1160(910-1500)$ & .08 \\
\hline FVC, $\%$ & $34.0(26.0-41.0)$ & $35.5(29.0-42.0)$ & $34.5(26.0-41.0)$ & .5 \\
\hline TLC, $\mathrm{L}^{*}$ & $2980(2360-3300)$ & $3110(2580-3340)$ & $2340(2010-3130)$ & .04 \\
\hline TLC, $\%$ & $47.0(39.0-54.0)$ & $48.0(43.0-55.0)$ & $43.5(35.0-53.0)$ & .2 \\
\hline \multicolumn{5}{|l|}{ Gas exchange $e^{\S}$} \\
\hline $\mathrm{PaO}_{2}, \mathrm{~mm} \mathrm{Hg}$ & $47.0(38.0-53.0)$ & $45.0(38.0-51.0)$ & $51.0(34.0-54.5)$ & .9 \\
\hline $\mathrm{PaCO}_{2}, \mathrm{~mm} \mathrm{Hg}$ & $45.0(41.0-50.0)$ & $45.0(41.0-50.0)$ & $44.0(41.0-48.5)$ & .5 \\
\hline Patients with hypercapnia & $29(63.0 \%)$ & $16(57.1 \%)$ & $12(75.0 \%)$ & .3 \\
\hline \multicolumn{5}{|l|}{ Cardiac assessment } \\
\hline Left ventricle ejection fraction $\%$ & $60.0(54.5-70.0)$ & $58.0(53.0-71.0)$ & $61.0(58.0-69.0)$ & .5 \\
\hline \multicolumn{5}{|l|}{ Right heart catheterization } \\
\hline PA systolic & $40.0(35.0-50.0)$ & $41.0(36.0-55.0)$ & $40.0(34.0-42.0)$ & .3 \\
\hline PA diastolic & $20.0(16.0-25.0)$ & $20.0(15.0-25.0)$ & $20.0(17.0-24.0)$ & .9 \\
\hline PA mean & $28.0(24.5-34.0)$ & $28.0(25.0-35.0)$ & $28.0(23.0-31.0)$ & 6 \\
\hline Wedge & $10.0(8.0-15.0)$ & $10.0(7.0-14.0)$ & $11.0(8.0-16.0)$ & .6 \\
\hline Cardiac index & $3.0(2.7-3.6)$ & $3.2(2.8-3.7)$ & $2.8(2.7-3.0)$ & .06 \\
\hline \multicolumn{5}{|l|}{ Exercise tolerance } \\
\hline 6-minute walk, m & $190(130-270)$ & $184(150-270)$ & 145 (125-258) & .2 \\
\hline
\end{tabular}

Boldface indicates statistical significance. $P A$, Pulmonary artery; $T L C$, total lung capacity; $F V C$, forced vital capacity.

*Plethysmographic measurements.

${ }^{\S}$ Room air; at rest.

TABLE 3. Multivariable regression values

\begin{tabular}{lccc}
\hline Variables (units) & $\begin{array}{c}\text { Hazard } \\
\text { ratio }\end{array}$ & $\begin{array}{c}\text { 95\% confidence } \\
\text { interval }\end{array}$ & $\boldsymbol{P}$ \\
\hline TLC (mL) & 0.99 & $0.99-1.01$ & .22 \\
$\begin{array}{l}\text { 6-minute walk }(\mathrm{m}), \text { by } 50 \mathrm{~m} \\
\quad \text { increase }\end{array}$ & 0.75 & $0.61-0.93$ & .003 \\
$\begin{array}{l}\text { Transplantation status* } \\
\text { * }\end{array}$ & 0.25 & $0.08-0.86$ & $\mathbf{. 0 3}$ \\
\hline
\end{tabular}

Boldface indicates statistical significance.

${ }^{*}$ Modeled as a time-dependent covariate.

used in the analysis. LTx was included in the Cox regression model as a time-dependent covariate. To enhance the accuracy of the model, the number of variables considered for the final Cox model was limited to 3 explanatory variables. ${ }^{19}$ Bootstrap resampling was used for model building. ${ }^{20}$ A total of 1000 samples of $80 \%$ of the initial data set were drawn at random with replacement. For each bootstrap sample, stepwise variable selection was performed. The 3 most frequently selected variables were included in the final model. Proportional hazards assumption was checked using a graphic method (log-log plots) and residual analysis. ${ }^{18}$ Data analysis was performed with Stata Statistical Software: Release 7.0 (Stata Corporation, College Station, Tex).

\section{Results}

Among all patients with interstitial lung disease placed on the waiting list during the study period, 46 patients were retrospectively selected who met the ATS criteria. Of these patients, 26 (56.5\%) had a lung biopsy before LTx showing a usual interstitial pneumonia (UIP) pattern, whereas no biopsy was performed in 20 cases. For patients who underwent LTx, the histologic examination of the explanted lung allowed the diagnosis of UIP in 5 patients who did not undergo biopsy before LTx. Fifteen patients in this study did not have confirmation of IPF. However, these patients fulfilled all the clinical, spirometric, and computed tomographic scan criteria of IPF defined by the ATS. Of the 46 patients with IPF placed on the waiting list, $28(61 \%)$ received transplants, $16(35 \%)$ died while on the waiting list, and $2(4 \%)$ are currently waiting for transplantation. Thirteen LTxs were performed during the first half of the study, and 15 LTxs were performed during the second half. Clinical characteristics of the patients are summarized in Table 1. All were dyspneic at rest (New York Heart Association class IV) and were given continuous nasal oxygen therapy. Consistent with their underlying advanced pulmonary fibrosis, the patients had a severe restrictive spirometric pattern, impaired oxygenation, and poor exercise tolerance (Table 2). Two thirds of the patients had hypercapnia at rest. The group of patients who underwent LTx and the group of patients who died on the waiting list differed significantly only by height and total lung capacity (Tables 1 and 2). In all but 1 case, the procedure was single LTx, whereas sequential bilateral LTx was performed once because of significant bronchiectasis in both lungs. The median waiting time for organs for the 28 patients who underwent LTx was 51 days (19-98 days). The median survival of patients on the waiting list (from placement on the list to death, patients being censored at time of transplant) was 136 


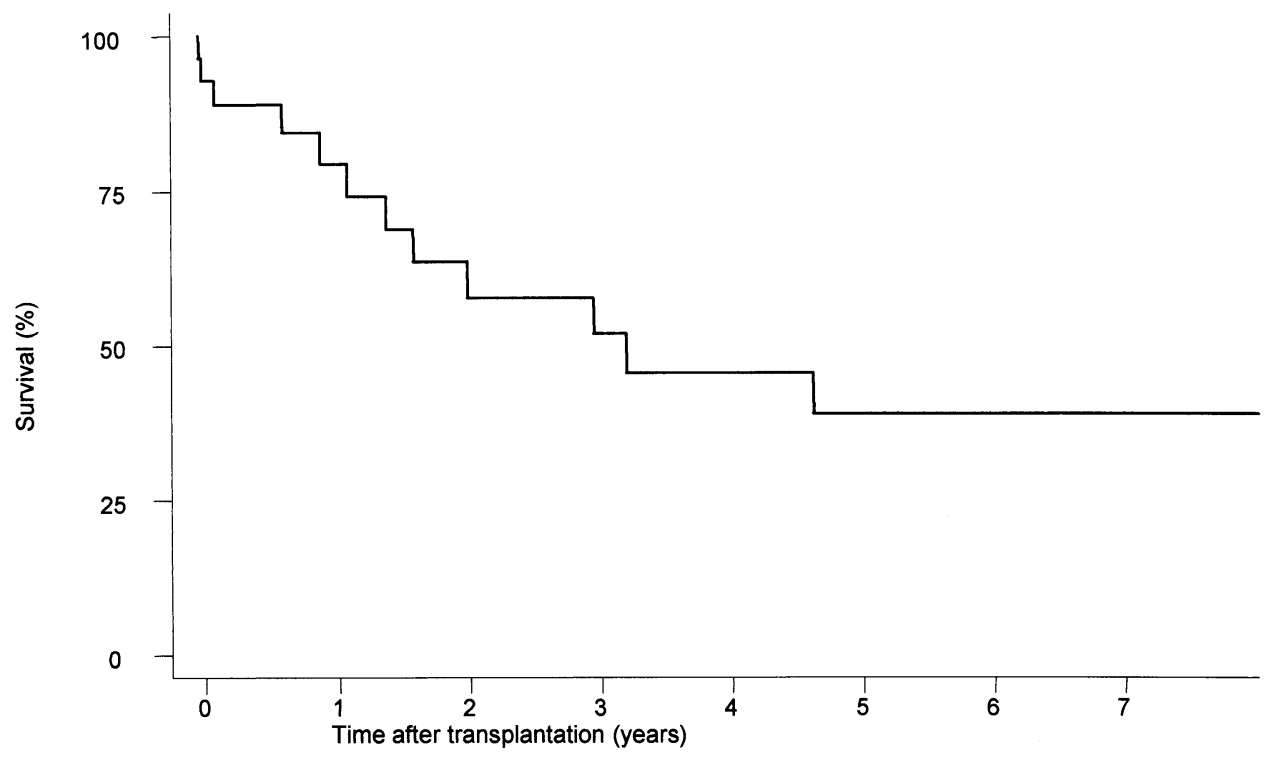

Number of patients at risk

\begin{tabular}{|llllllll|}
\hline 28 & 18 & 12 & 10 & 7 & 6 & 6 & 6 \\
\hline
\end{tabular}

Figure 1. Survival after LTx.

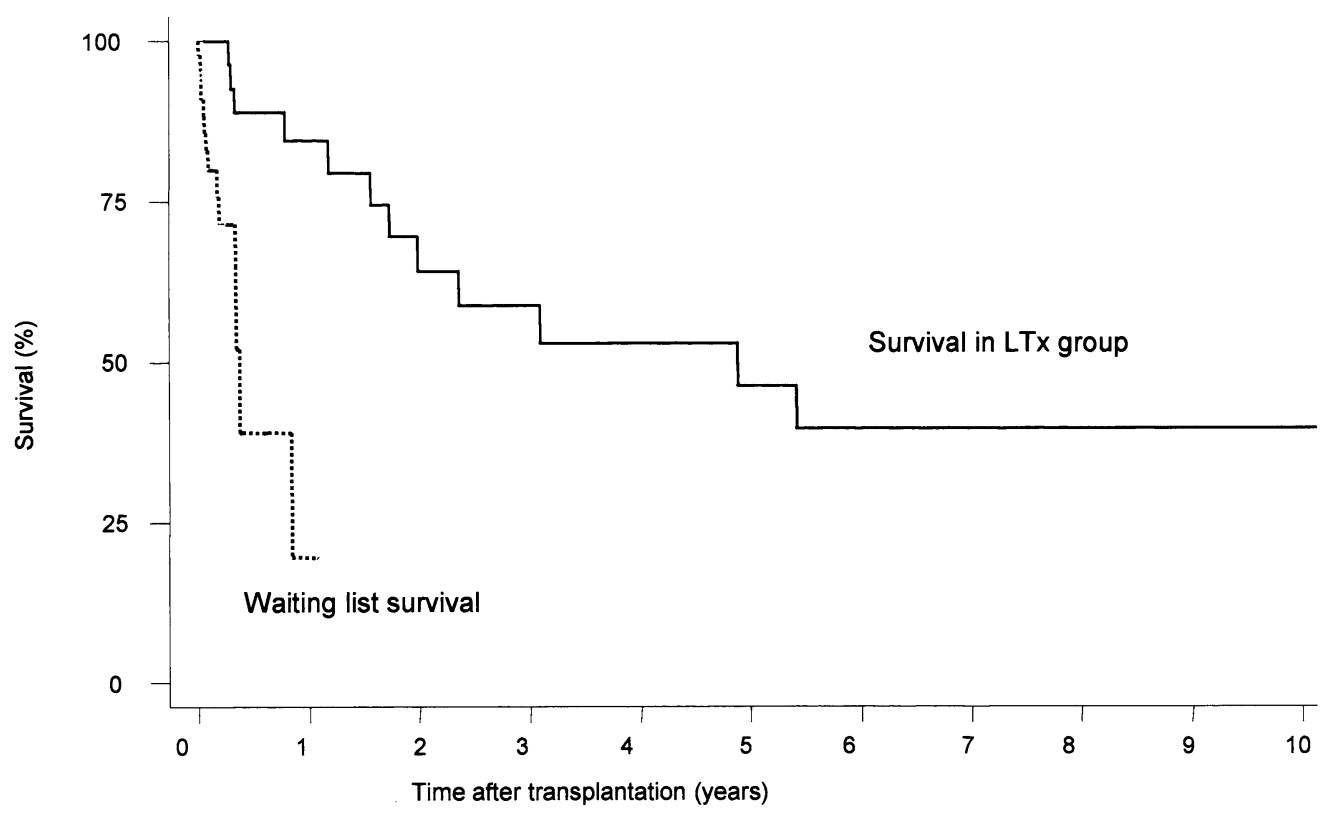

Figure 2. Survival on waiting list (from placement on the list to death or transplantation) compared with survival of patients who underwent LTx (from placement on the list including posttransplantation survival).

days (69-307 days). Survival after LTx (Figure 1) was 93\% at day $30,79.4 \%$ at 1 year, $63.5 \%$ at 2 years, and $39 \%$ at 5 years. Figure 2 shows survival on the waiting list (ie, survival from placement on the waiting list until death or transplantation) compared with survival in the group of patients who underwent LTx (ie, survival from placement on the waiting list, including posttransplantation survival). All the deaths in patients on the waiting list were ascribed to respiratory failure. By multivariate analysis, only the 6-minute walk test and amount of oxygen supply at the time 
of inscription on the waiting list were found associated with death in the patients on the waiting list. Of the 28 patients receiving LTxs, 12 have died and 16 were alive at the end of the study period. The causes of death were sepsis in 6 patients, chronic rejection in 4 patients, carcinoma in 1 patient, and primary graft failure in 1 patient. The 3 variables included in the final multivariable model were transplantation status, total lung capacity, and 6-minute walk test. In a multivariable analysis, only transplantation status (hazard ratio [HR]: $0.25 ; 95 \%$ confidence interval [CI]: $0.08-0.86 ; P: 0.03$ ) and 6-minute walk test (HR: 0.75; 95\%; CI: $0.61-0.93 ; P: .003)$ remain significantly associated with mortality (Table 3 ).

\section{Discussion}

The main result of this study is that LTx in patients with IPF allows a $75 \%$ (CI: $14 \%-92 \%$ ) reduction in the risk of death when the patients are accepted on our waiting list. Because a randomized controlled trial comparing LTx with medical management alone for patients with end-stage lung disease seems unethical, various approaches may help in assessing survival improvement given by LTx. The first approach is to compare the survival of patients who underwent LTx with that of a historical cohort of patients with several causes of end-stage lung diseases. ${ }^{21}$ However, in that case, the 2 groups are not really comparable, because patients listed for transplantation form a highly selected sample of patients. A more appropriate approach is to compare survival rates between patients receiving LTx with those remaining on the waiting list. ${ }^{22}$ Such an approach may have some drawbacks, because the 2 groups are not really comparable. On the one hand, the patients who received transplants are in a way more resistant than those who did not, because they are able to wait until LTx, and on the other hand, some centers attempt to give lung grafts to patients with the poorest life expectancy. The best approach is probably the method previously used by Cox and Oakes, ${ }^{23}$ making a multivariable model that includes transplantation as a time-dependent covariate. This powerful model allows the introduction of potential confounders to further reduce selection bias. Such an approach has already been used in several studies. ${ }^{10,11,24,25}$ For example, Sharples and colleagues ${ }^{25}$ analyzed the survival of 67 patients with cystic fibrosis referred for heart-lung transplantation. After adjustment for potential confounders, they found that LTx for these patients decreased the risk of death by approximately $50 \%$. However, this result was not statistically significant. Using the same statistical approach, Geertsma and colleagues ${ }^{10}$ studied 157 patients with various underlying lung diseases who were listed for LTx. They found a 55\% reduction of the risk of death. However, they did not calculate a separate HR according to the diagnosis. Among these patients, only 9 had IPF. On the basis of data from the United Network for
Organ Sharing, Hosenpud and colleagues ${ }^{11}$ also analyzed the effect of diagnosis on the survival benefit of LTx for end-stage lung disease. The results were adjusted for race, sex, and age by means of multivariable analysis. The clearest benefit occurred in the cystic fibrosis group, whereas it was not significant for interstitial pulmonary fibrosis or emphysema. In this latter study, IPF was not separated from other interstitial lung diseases. More recently, Aurora and colleagues $^{24}$ studied 124 children with cystic fibrosis accepted for LTx during a 10-year period. After adjustment on 7 factors previously found as potential confounders, LTx was significantly associated with a reduction of $69 \%$ in the overall risk of death. By analyzing all the patients consecutively registered for first LTx on the Eurotransplant waiting list for a 7-year period, De Meester and colleagues ${ }^{9}$ found a beneficial effect of LTx for patients with pulmonary fibrosis (IPF and sarcoidosis), cystic fibrosis, emphysema, and pulmonary hypertension. However, the methodologic approach used raises several concerns. They used a timedependent nonproportional hazard analysis to assess the benefit offered by transplantation. However, this model did not take into account potential confounding variables, and no test of statistical significance was provided.

Given these results, we decided to study the effect of LTx on the survival of patients in a homogeneous sample of patients listed for LTx in our center with a diagnosis of IPF. Using Aurora and colleagues' statistical approach, ${ }^{24}$ we found a reduction of $75 \%$ in the risk of death after adjustment for variables believed to be potential confounders. The following assumptions and limitations to our study should be emphasized. First, using a time-dependent proportional hazard model, we assume a constant HR over time. These limitations led Hosenpud and coworkers ${ }^{11}$ to use a timedependent nonproportional hazards analysis to assess the role of LTx on survival. However, we paid critical attention to check that this major assumption of the Cox model was not violated. Graphic inspection of the log-log plots and residual analysis did not detect a clear violation of proportional hazards assumption. A second assumption in our analysis is that in our model we took into account the major risk factors for transplant-related mortality. In light of the small study sample size, we chose to limit the number of explanatory variables to 3 . Although we included several factors known to influence the survival of patients with end-stage lung diseases or IPF, we cannot exclude the possibility that other factors, not studied in our analysis or unidentified, may have affected the outcome. Moreover, the decision and timing of listing involve subjective events difficult to account for. The small size of this study is of concern. Including in the analysis all patients with interstitial disease irrespective of its origin would have reinforced the statistical power. However, it might have resulted in a less homogeneous sample of patients leading to erroneous 
conclusions, because patients with secondary pulmonary fibrosis have different prognoses than patients with IPF. ${ }^{12}$ In the same way, we could have pooled our data with those of other transplantation centers to increase the statistical power of our study. However, we considered that this approach would have led to a more heterogeneous sample, because the participating centers were highly unlikely to have a uniform listing policy for all patients. A third limitation is the lack of histologic specimens showing a UIP pattern in 15 cases (10 patients who died before LTx and 5 patients who underwent LTx). Although these patients fulfilled all the ATS criteria for IPF, diagnosing without a histologic specimen is less certain and could have introduced a bias in the analysis. It must be noted that we did not consider LTx in our center for patients with IPF when associated with severe pulmonary hypertension. Because pulmonary hypertension is associated with a decrease in posttransplant survival regardless of the underlying disease, our results should be limited to patients with IPF and without significant pulmonary hypertension.

The present study demonstrates the survival benefit offered by LTx in patients with IPF. The influence of the organ allocation scheme on our results must be emphasized. The organ allocation scheme in use in France, as in other countries, ${ }^{24}$ is not based on the waiting time of each recipient. This policy allows the attending physician to prioritize the patients with the poorest life expectancy. It results in a very short waiting time for patients with IPF and in a longer waiting time for patients with longer life expectancy. In comparison, the median waiting time of the other patients on our list is approximately 10 months. However, despite this short waiting time, the fatality rate on the waiting list remains high in patients with IPF. In our center, 35\% of patients with IPF died on the waiting list compared with $15 \%$ of patients with other diagnoses. The fatality rate of our patients listed for LTx, which is much higher than that described by Hosenpud and colleagues ${ }^{11}$ in the United Network for Organ Sharing registry, helps to demonstrate a beneficial effect of LTx in our study. This high fatality rate could be relative to the very end stage of the disease at the time of listing (New York Heart Association class IV, hypercapnia at rest in the majority of patients, and dependency on high flow of oxygen). Thus, we think that the conclusion of our study should be restricted to centers with the same organ allocation policy as ours. Among the variables studied, only exercise capacity assessed by the 6-minute walk test was associated with mortality. These findings should be interpreted cautiously because we lack statistical power to reliably assess predictors of mortality. The aim of including these variables in this study was not to study predictors of mortality for patients with IPF who were listed for LTx but to control potential biases when assessing the effect of LTx on survival.

\section{Conclusion}

Unless survival without transplantation improves dramatically by means of new medical treatments, LTx seems to be effective in reducing the risk of death for patients with IPF without secondary pulmonary hypertension.

\section{References}

1. Idiopathic pulmonary fibrosis: diagnosis and treatment. International consensus statement. American Thoracic Society (ATS), and the European Respiratory Society (ERS). American Thoracic Society. Am J Respir Crit Care Med. 2000;161:646-64.

2. American Thoracic Society/European Respiratory Society International Multidisciplinary Consensus Classification of the Idiopathic Interstitial Pneumonias. This joint statement of the American Thoracic Society (ATS), and the European Respiratory Society (ERS) was adopted by the ATS board of directors, June 2001 and by the ERS Executive Committee, June 2001. Am J Respir Crit Care Med. 2002; 165:277-304.

3. Gross TJ, Hunninghake GW. Idiopathic pulmonary fibrosis. $N$ Engl J Med. 2001;345:517-25.

4. Bjoraker JA, Ryu JH, Edwin MK, Myers JL, Tazelaar HD, Schroeder DR, et al. Prognostic significance of histopathologic subsets in idiopathic pulmonary fibrosis. Am J Respir Crit Care Med. 1998;157:199203.

5. Mogulkoc N, Brutsche MH, Bishop PW, Greaves SM, Horrocks AW, Egan JJ. Pulmonary function in idiopathic pulmonary fibrosis and referral for lung transplantation. Am J Respir Crit Care Med. 2001; 164:103-8.

6. King TE Jr, Tooze JA, Schwarz MI, Brown KR, Cherniack RM. Predicting survival in idiopathic pulmonary fibrosis: scoring system and survival model. Am J Respir Crit Care Med. 2001;164:1171-81.

7. King TE Jr, Schwarz MI, Brown K, Tooze JA, Colby TV, Waldron JA Jr, et al. Idiopathic pulmonary fibrosis: relationship between histopathologic features and mortality. Am J Respir Crit Care Med. 2001;164:1025-32.

8. Hosenpud JD, Bennett LE, Keck BM, Fiol B, Novick RJ. The Registry of the International Society for Heart and Lung Transplantation: fourteenth official report-1997. J Heart Lung Transplant. 1997;16:691712.

9. De Meester J, Smits JM, Persijn GG, Haverich A. Listing for lung transplantation: life expectancy and transplant effect, stratified by type of end-stage lung disease, the Eurotransplant experience. J Heart Lung Transplant. 2001;20:518-24.

10. Geertsma A, Ten Vergert EM, Bonsel GJ, de Boer WJ, van der Bij W. Does lung transplantation prolong life? A comparison of survival with and without transplantation. J Heart Lung Transplant. 1998;17:511-6.

11. Hosenpud JD, Bennett LE, Keck BM, Edwards EB, Novick RJ. Effect of diagnosis on survival benefit of lung transplantation for end-stage lung disease. Lancet. 1998;351:24-7.

12. Wells AU, Cullinan P, Hansell DM, Rubens MB, Black CM, Newman-Taylor AJ, et al. Fibrosing alveolitis associated with systemic sclerosis has a better prognosis than lone cryptogenic fibrosing alveolitis. Am J Respir Crit Care Med. 1994;149:1583-90.

13. International guidelines for the selection of lung transplant candidates. The American Society for Transplant Physicians (ASTP)/American Thoracic Society (ATS)/European Respiratory Society (ERS)/International Society for Heart and Lung Transplantation (ISHLT). Am J Respir Crit Care Med. 1998;158:335-9.

14. Sundaresan S, Trachiotis GD, Aoe M, Patterson GA, Cooper JD. Donor lung procurement: assessment and operative technique. Ann Thorac Surg. 1993;56:1409-13.

15. Cooper JD, Pearson FG, Patterson GA, Todd TR, Ginsberg RJ, Goldberg M, et al. Technique of successful lung transplantation in humans. J Thorac Cardiovasc Surg. 1987;93:173-81.

16. Bisson A, Bonnette P. A new technique for double lung transplantation. "Bilateral single lung" transplantation. J Thorac Cardiovasc Surg. 1992;103:40-6. 
17. Thabut G, Brugiere O, Leseche G, Stern JB, Fradj K, Herve P, et al. Preventive effect of inhaled nitric oxide and pentoxifylline on ischemia/reperfusion injury after lung transplantation. Transplantation. 2001;71:1295-300.

18. Hosmer DW, Lemeshow S. Applied survival analysis: regression modeling of time to event data. New York: John Wiley \& Sons; 1999.

19. Harrell FE Jr, Lee KL, Califf RM, Pryor DB, Rosati RA. Regression modelling strategies for improved prognostic prediction. Stat Med. 1984;3:143-52.

20. Harrell FE Jr, Lee KL, Mark DB. Multivariable prognostic models: issues in developing models, evaluating assumptions and adequacy, and measuring and reducing errors. Stat Med. 1996;15:361-87.

21. Meyers BF, Lynch JP, Trulock EP, Guthrie T, Cooper JD, Patterson GA. Single versus bilateral lung transplantation for idiopathic pulmo- nary fibrosis: a ten-year institutional experience. J Thorac Cardiovasc Surg. 2000;120:99-107.

22. Ramsey SD, Patrick DL, Albert RK, Larson EB, Wood DE, Raghu G. The cost-effectiveness of lung transplantation. A pilot study. University of Washington Medical Center Lung Transplant Study Group. Chest. 1995;108:1594-601.

23. Cox DR, Oakes D. Analysis of survival data. London: Chapman and Hall; 1984.

24. Aurora P, Whitehead B, Wade A, Bowyer J, Whitmore P, Rees PG, et al. Lung transplantation and life extension in children with cystic fibrosis. Lancet. 1999;354:1591-3.

25. Sharples L, Hathaway T, Dennis C, Caine N, Higenbottam T, Wallwork J. Prognosis of patients with cystic fibrosis awaiting heart and lung transplantation. J Heart Lung Transplant. 1993;12:669-74.

\section{Authoritative}

The Journal of Thoracic and Cardiovascular Surgery is the most frequently cited thoracic/cardiovascular surgery journal in the Science Citation Index. An article in JTCVS is cited on average almost twice as often as those in the closest cardiothoracic journal. 